Abstracta Iranica Abstracta Iranica

Revue bibliographique pour le domaine irano-aryen

Volume 26 | 2005

Comptes rendus des publications de 2003

\title{
"The Williamson Collection Project: Sasanian and Islamic Survey Ceramics from Southern Iran, Current Research ». Iran 41, (2003), pp. 345 - 348.
}

Karin Mosig-Walburg

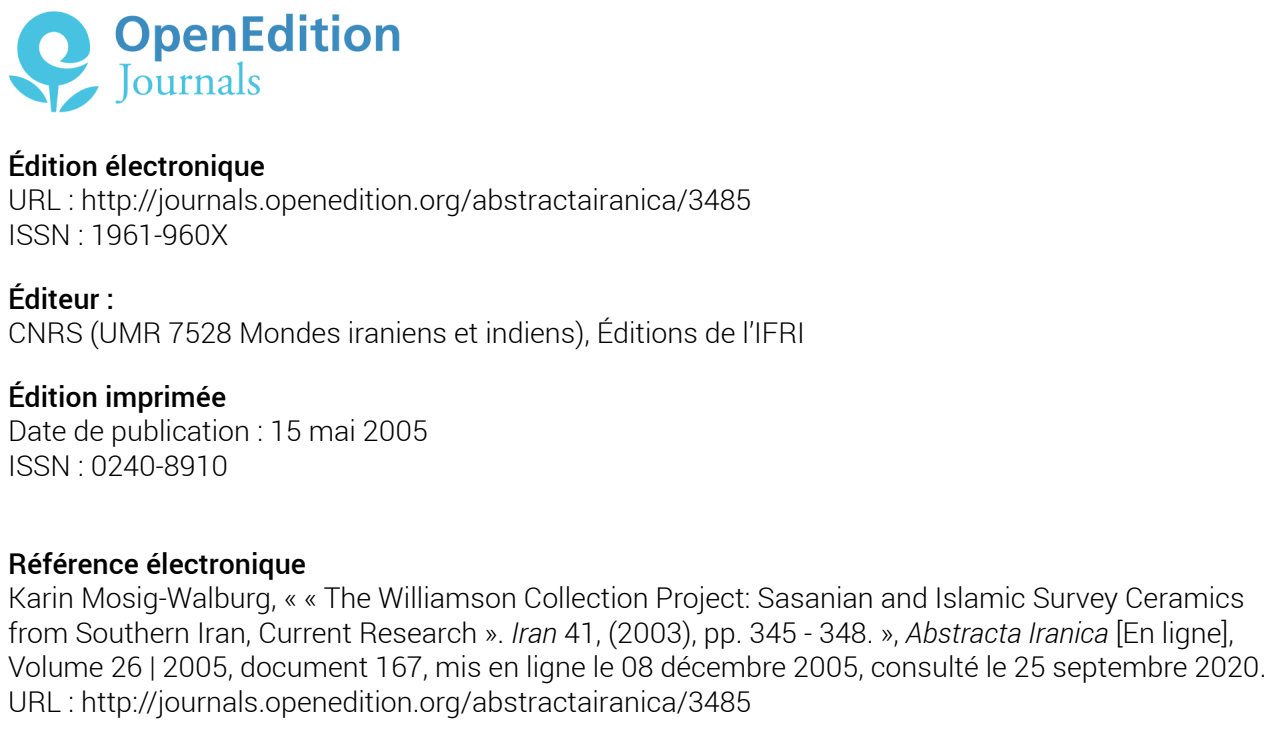

Ce document a été généré automatiquement le 25 septembre 2020.

Tous droits réservés 
«The Williamson Collection Project: Sasanian and Islamic Survey Ceramics from Southern Iran, Current Research ». Iran 41, (2003), pp. $345-348$.

\author{
Karin Mosig-Walburg
}

1 Le Williamson Collection Project, exécuté par l'Université de Durham depuis le mois d'octobre de l'année 2001, a pour but une documentation et une exploitation scientifiques des trouvailles de poterie sasanide et arabe, faites par le feu Williamson au cours de ses surface-surveys entre 1968 et 1971 en Iran, le long de la côte entre Bushehr et Jask et dans les provinces de Fars et de Kirman. A la mort prématurée de Williamson les trouvailles et les documentations se trouvaient en désordre, des documents importants faisaient défaut. L'A. présente les résultats préliminaires du projet (un résultat important est de savoir que la collection ne représente qu'un tiers de l'ensemble des trouvailles faites, dont deux tiers sont restés en Iran) et il annonce le procédé futur.

\title{
INDEX
}

Thèmes : 3.2.3. Séleucides, Parthes et Sassanides 
AUTEURS

KARIN MOSIG-WALBURG

Université de Francfort 